detached and destroyed during uncontrolled descent.

However comforting or worrying these figures, there is no doubt that the gloomy prediction of Eccclesiastes that "they shall be afraid of that which is high" has taken on a new and urgent meaning. President Carter has already expressed his willingness to be a party to a treaty banning the use of reactors from orbit. For the Soviet side, Academician Leonid Sedov has said in a TASS interview on Soviet radio that the errant satellite was in no way the "flying nuclear bomb" which some "absurd rumours" would make it. There were not and could not be any weapons aboard, he said, and those who spread such tales were trying to undermine the basic principles of international cooperation in the exploration and peaceful use of outer space.

In spite of Sedov's reassurances, it seems likely that Kosmos-954 did have certain military potentialities. Technically, it was a low orbit satellite for ocean surveillance. The presence of a reactor aboard (as opposed to a weaker isotope source) implies the use of powerful radar for monitoring ship movements, which would suggest that the terms of reference of the international agreements on the peaceful uses of both space and atomic energy were being somewhat stretched. Any future agreement on reactors in orbit might well have to re-examine the definition of 'peaceful' in this context.

Doubtless as a further reassurance, Sedov presented the official Soviet view of the accident: a sudden depressurisation of the satellite while beyond the range of Soviet tracking facilities. Since depressurisation was so rapid, it is assumed that Kosmos-954 collided with "some other object of natural or artificial origin".

Strangely, Sedov gave the significant date as January 6-the date of the "depressurisation". Yet according to US observers, the satellite was already misbehaving on December 17. The two reports are not incompatible-if the satellite was already out of control, it might well have come into contact with some other artificial object or debris which it normally should not have encountered. This, however, is not Sedov's story: he maintains that the on-board systems became inoperative only as a result of the January 6 impact-one more minor mystery to add to the story of Kosmos-954.

One fact, however, has already emerged quite clearly-the cost of the search and recovery operations. According to Canadian Prime Minister Pierre Trudeau, by last weekend this had reached one million dollars and was rising daily.

Vera Rich

\title{
Britain's big science on the baseline
}

AFTER four months in office, Professor Geoff rey Allen, Chairman of the UK's Science Research Council (SRC), is pleasantly surprised that the Advisory Board for the Research Councils (ABRC) is not as hostile to basic science as he had been led to believe by his predecessor, Sir Sam Edwards.

Professor Allen, speaking at a British science writers' luncheon, said that in spite of the proposed $1.7 \%$ annual cut in the SRC's budget over the next four years, announced with the science vote last month, the outlook for science in the UK is looking slightly up. His cautious optimism is founded on the ABRC's decision to award the SRC greater shares than it could expect, in proportion to its annual expenditure, of the extra $£ 4$ million added to the science vote last October and of the $£ 4.5$ million to be spent on capital work in $1978 / 79$.

A beneficiary of that optimism could be 'big science', long since neglected for research designated of national importance. "Nuclear physics, astronomy and space research have been battered" admits Professor Allen. For nuclear physics, in particular, he agrees that funding is now at the minimum viable level-almost. "We've nearly reached the baseline" he says, "which we must maintain to support a UK presence in nuclear physics".

And Professor Allen seems determined to have a say in the fate of British nuclear physics. Last December, he was at his own request appointed to the Council of the European Centre for Nuclear Research (CERN) in Geneva, now the major recipient of Britain's funds for high energy physics. He has already expressed his view that CERN's annual budget should be planned to remain at a plateau of about Sw Fr 560 million. The budget for 1978 is Sw Fr 615 million and many countries would like to see future budgets stabilise at about Sw Fr 600 million.

Not all British nuclear physicists, however, are in agreement with Professor Allen's baseline. Dr G. Stafford, Director of the UK Rutherford Laboratory thinks that a Sw Fr 560 million budget at CERN "will mean losing out on basic experiments". Such a low sum, he claims, "takes no regard for future development. By the 1980s existing machines will be old and at that level of funding we would not be able to replace them". On one point, though, Allen and Stafford do agree; that if future projections for the total UK nuclear physics budget are met, involving a $25 \%$ cut in spending over the next five years, then there would be insufficient funds for a home-based programme and UK nuclear physics would be at an end. Stafford feels that the funding is at an absolute minimum.

The fate of high energy physics, however, is being pursued on another level. At the end of this week, Shirley Williams, Secretary of State for Education and Science, and a powerful lobbyist for the interests of scientists in the UK cabinet, will visit CERN.

The state in Britain of the other big science-astronomy and space science is perhaps not quite so critical as that of high energy physics. Provided that there is no large cutback in funds over the next few years, radio astronomers should be able to maintain a competitive programme. Plans for a millimetre-wave radio telescope already have SRC approval: all that is now needed is Treasury approval for the $£ 4-5$ million it is likely to cost. And Jodrell Bank has plans to go ahead with extending its multi-telescope interferometer at an estimated cost of $£ 2^{\circ}$ million.

In astronomy it is the X-ray astronomers and space scientists who are showing most concern over their futures. Professor Ken Pounds of Leicester University claims that British X-ray astronomy is in a "fairly critical state". Its international reputation is higher than it has ever been but the prospects for the future are poor unless funding can be maintained at least at the present level. "If the UK is to get the best out of its subscription to the European Space Agency (ESA), then it must have a comparable home programme". But ESA can only fund one major new project in any particular discipline every two years, so each discipline is catered for approximately once every ten years. At the moment, for example, ESA has only one satellite for X-ray studies, EXOSAT. Therefore the UK must be able to bid for space on other satellites including NASA's Space Shuttle. This means maintaining a home based programme to the tune of $£ 5-6$ million.

Professor Allen's concern, however, is not entirely with the problems of 'big science'. He sees as one of his immediate priorities 'making Sam's plans succeed" by continuing to give special attention to areas of national importance including microelectronics, marine technology and polymer engineering and making sure that schemes to improve collaboration between industry and universities are implemented.

Judy Redfearn 